\title{
Experimental Evidence on Returns to Capital and Access to Finance in Mexico
}

\author{
David McKenzie and Christopher Woodruff
}

\begin{abstract}
A strong theoretical argument for focusing on access to finance is that financial market imperfections can result in large inefficiencies, as firms with productive investment opportunities underinvest. Lack of access to finance is a frequent complaint of microenterprises, which account for a large share of employment in developing countries. However, assessing the extent to which a lack of capital affects their business profits is complicated by the fact that business investment is likely to be correlated with a host of unmeasured characteristics of the owner and firm, such as entrepreneurial ability and demand shocks. In a randomized experiment that gave cash and in-kind grants to small retail firms, providing an exogenous shock to capital, the shock generated large increases in profits, with the effects concentrated among firms that were more financially constrained. The estimated return to capital was at least 20-33 percent a month-three to five times higher than market interest rates. JEL codes: O17, O16, C93
\end{abstract}

Lively microenterprise sectors are a dominant feature in urban areas of low- and middle-income countries, where as much as one-third of the labor force is selfemployed. A plurality of owners of microenterprises is involved in retail trade (street vendors and owners of small shops and restaurants). These vendors earn their living using their own labor and small amounts of capital. They generally lack access to loans from formal financial institutions, relying on their own savings and perhaps informal loans from family members or friends. Surveys indicate that the lack of access to finance is one of their most often mentioned complaints.

How much does the lack of capital affect enterprise earnings? At least one study of Mexico suggests that the effect is considerable. McKenzie and

David McKenzie (corresponding author) is a senior economist in the Finance and Private Sector Research Unit of the Development Research Group at the World Bank; his email address is dmckenzie@ worldbank.org. Christopher Woodruff is an associate professor of economics at the Graduate School of International Relations and Pacific Studies at the University of California at San Diego; his email is cwoodruff@ucsd.edu. The authors thank the editor and three anonymous referees for their helpful comments. They thank Bob Cull for his insights on the Mexican financial sector and his collaboration in this project. Matthias Schündeln and participants at the World Bank Access to Finance conference provided useful comments. The authors appreciate financial support for this project from the World Bank. Data OPM carried out the survey work on which the article is based.

THE WORLD BANK ECONOMIC REVIEW, VOL. 22, NO. 3, pp. 457-482

doi:10.1093/wber/lhn017

Advance Access Publication November 2, 2008

(C) The Author 2008. Published by Oxford University Press on behalf of the International Bank for Reconstruction and Development / THE WORLD BANK. All rights reserved. For permissions, please e-mail: journals.permissions@oxfordjournals.org 
Woodruff (2006) use data from the Mexican National Survey of Microenterprises (ENAMIN), a cross-section conducted every two years during 1992-98, to estimate returns to capital. They find returns in the range of 10-15 percent a month for the smallest firms, those with capital stocks of less than $\$ 500$. For each additional $\$ 100$ invested in the enterprise, earnings rise \$10-\$15 a month. Although provocative, the returns estimated by McKenzie and Woodruff are subject to several concerns. A primary concern is whether capital investment is correlated with unmeasured ability, resulting in conflation of returns to capital with returns to ability. McKenzie and Woodruff address this issue with several measures of ability, but each is imperfect. The use of standard panel data would not resolve all of the issues, because changes in capital stock between rounds of a panel would be endogenous to unmeasured shocks to demand for a firm's output, among other factors.

To deal with these concerns, the authors designed a randomized experiment to generate data that yield a consistent measure of returns to capital in microenterprises. Data were collected from a panel of microenterprises in the city of León, Guanajuato, in Mexico, over five quarters. After the first through fourth rounds of the survey, treatments were administered in the form of either cash or equipment to randomly selected enterprises in the sample. The treatments generated positive shocks to capital stock. These shocks were random and thus uncorrelated with either the ability of the enterprise owner or the prospects for the business.

A 1,500 peso $(\$ 140)$ treatment is estimated to increase monthly profits by at least 292-487 pesos, a marginal return to capital of 20-33 percent. The estimates are robust to controls for possible treatment spillovers and attrition. These returns are at the upper end of the range estimated by McKenzie and Woodruff (2006) using nonexperimental methods. The treatment effect is then interacted with various measures of financial constraints and access to finance. The return is much higher $(70-79$ percent) for firms that report being financially constrained and much lower for firms that report that lack of finance is not a constraint. Indeed, the possibility of no return for non-credit-constrained firms cannot be rejected. Finance is reported to be less of a constraint for firms that are formal, have more educated owners, and have owners whose fathers owned a business.

An unbiased estimate of returns to capital has important policy implications in several areas. First, the returns from investment provide an upper bound of interest rates that borrowers are willing to pay to microlending organizations. Higher returns imply a higher likelihood of developing financially sustainable microlenders. There is considerable debate about the sensitivity of microfinance demand to higher interest rates (Morduch 2000; Karlan and Zinman 2008a). Mexico has a very underdeveloped microlending sector relative to other low- and middle income countries. High returns may suggest the scope for more lending.

Second, if returns are below some investment threshold, these low returns may act as an entry barrier, preventing high-ability entrepreneurs without 
access to capital from entering. If returns to capital are high at very low levels of investment, capital-constrained entrepreneurs should be able to enter and grow to a desired size by reinvesting profits earned in the enterprise. In this case, capital constraints will have short-term costs but fewer long-term effects on outcomes. High returns at low to very low capital stock levels suggest that credit constraints will not lead to poverty traps.

The recent literature generally finds high rates of return to capital in small-scale enterprises. With one exception, it uses nonexperimental approaches to estimate the return to capital. Banerjee and Duflo (2004) use changes in laws forcing Indian banks to make preferential loans to certain groups of firms (considerably larger than those studied here) to identify changes in access to finance among the firms. They conclude that returns to capital are 74-100 percent a year. Udry and Anagol (2006) estimate annual returns to capital among small-scale agricultural producers on median-sized plots in Ghana at 50 percent for traditional crops and 250 percent for nontraditional crops. They also calculate the effective discount rates from the market for used taxi parts. Using data on prices and useful lives of used taxi parts, they estimate the annual discount rate among taxi drivers to be 60 percent, suggesting that the shadow value of capital among taxi drivers is at least this high. Kremer and others (2007) creatively use the data on stock-outs and discounts for bulk purchases to estimate annual returns of at least 113 percent for rural retail shops in Kenya.

Randomized experiments have become increasingly popular in development economics as a way to overcome many of the identification concerns that can arise with nonexperimental approaches. Many of the earliest applications were in education and health (see, for example, Kremer 2003). Several recent articles use randomized experiments to examine some aspects of access to finance, including the impact of consumer credit (Karlan and Zinman 2008b) and the comparative roles of joint and individual liability in microfinance groups (Giné and Karlan 2006). The only other study the authors are aware of that takes an experimental approach to relaxing capital constraints on firms is work on Sri Lanka by De Mel and others (2008). Using a similar experimental design, that study find returns for similar size enterprises in both the retail and manufacturing sectors in the range of 5-7 percent a month, several times higher than market interest rates, with lower returns for females than males.

This article focuses on male-owned firms in the retail trade industry. It shows that the high returns for this group found in Sri Lanka generalize to a very different country context. The article also breaks out returns for firms with and without prior access to finance.

The next section describes the sample selection, the relevant portion of the survey instrument, and the data. Section II describes the experimental intervention. Section III presents the estimation of the treatment effects, and Section IV looks at the effect of access to finance on returns. The last section discusses the results and provides some concluding remarks. 


\section{The Sample and the Data}

Data come from a panel survey of microenterprises in the city of León, in the state of Guanajuato, Mexico. León is the fifth largest city in Mexico, with a metropolitan area population of about 1.4 million. The city is the center of Mexico's shoe and leather industries and home to a vibrant microenterprise sector covering the usual range of activities found in the developing world.

The initial survey was conducted in November 2005, reflecting data from October 2005. Subsequent surveys were administered quarterly, with the fifth and last survey conducted in November 2006. The first round of the panel includes 207 firms. $^{1}$ Of these firms, 182 are resurveyed in the first follow-up (February 2006) and 137 firms in the fifth round. Profits are reported by 114 firms in all five rounds of the survey and by 161 firms in at least three rounds. Attrition is thus of some concern in analyzing the results of the survey, as discussed below.

\section{The Sample}

The authors set out to select a sample of enterprises with less than 10,000 pesos (about $\$ 1,000$ ) in capital stock excluding land and buildings. An upper limit was placed on capital stocks because the results of McKenzie and Woodruff (2006) suggest that returns are highest at very low levels of capital. Doing so eliminates firms that have managed to grow above a certain size, but the vast majority of firms starting small in the retail sector never grow large. Moreover, the sample also includes young firms, which might grow above this threshold in the future.

The project budget was sufficient to follow a sample of about 200 firms for five quarters. Cross-sectional data on similar enterprises from the ENAMIN indicate that variances in the reported data on key statistics such as profits and income are very high. To reduce the expected variance and increase the expected power of the estimates based on the data, the authors limited the sample to enterprises engaged in retail trade and owned by men ages 22-55. Only owners working at least 35 hours a week were included in the baseline period.

The retail trade sector covers a wide range of typical small-scale businesses found in many developing economies. Examples include sellers of groceries, flowers, DVDs, shoes, small toys, batteries, balloons, tacos, newspapers, bread, fruit, watches, seafood, beer, wallets, leather bags, handicrafts, perfume and cosmetics, corn holders, chilies, juices, books, and clothing.

The sample frame is based on the 10 percent public use sample of the 2000 population census for León. These data indicate that 79 percent of the full-time self-employed are male and that 80 percent of the male full-time self-employed

1. Initially, the first round included 220 firms. Thirteen firms that did not meet the original sample criteria were eliminated before the second round of the survey began. 
are ages 22-55. Wholesale and retail trade is the most common industry among men in the age group, accounting for more than 29 percent of full-time self-employment. The next most common industries are manufacturing (26 percent), personal services (12 percent), and construction (9 percent).

The data were examined at the level of the smallest geographic unit available in the public sample, the primary sampling unit (unidad primaria de muestreo, or UPM). An average UPM in León contains about 17,000 people, about 3,400 of them men ages 22-55. For each UPM, the average education level, the percentage self-employed in the retail sector, and the percentage of households with a male household head present were calculated. These data were used to select 20 UPMs with high rates of retail self-employment and modest average levels of education.

Attention was restricted to UPMs satisfying these criteria, for two reasons. The first was cost and logistics. The survey randomly selected blocks within these UPMs and administered a short screening survey to both households and small enterprises. Restricting the survey to UPMs with high incidences of selfemployment ensured that the screening survey would capture enough firms with characteristics fitting the criteria and that the firms would not be so scattered throughout the city that it would be difficult to administer the experiment and follow-up surveys. The screening survey identified enterprises owned by men ages 22-55 in the retail sector operating without paid employees. Enterprises with paid employees are likely to exceed the upper limit of 10,000 pesos of capital stock, so the lack of paid employees was used as an initial screen for capital stock. The screening survey also asked respondents the value of their capital stock excluding land and buildings, measured at replacement cost. The second reason for focusing on UPMs with a high incidence of selfemployment and modest average levels of education is that these are potentially the areas in which microfinance or other access to finance interventions would be targeted (that is, areas in which many low-income households depend on self-employment). ${ }^{2}$

The survey data are not representative of the full sample of own-account workers (table 1). The mean level of monthly income in the sample $(2,547$ pesos) is less than half that of own-account workers in the census $(5,671$ pesos). The difference in median income is smaller (2,213 compared with 4,286 pesos a month) but still considerable. The comparison is not altered when the census sample is limited to own-account workers in the retail sector. Almost 12,000 prime-age men in León-about 30 percent all male ownaccount workers-are own-account workers in the retail trade sector. ${ }^{3}$

2. Had UPMs been chosen randomly, it is possible that by pure chance all the microenterprises in the survey could have come from relatively wealthy areas, where few other microenterprises operate.

3. The factor weights included in the census suggests that there are almost 30,500 own-account workers in the city's retail sector, including both males and females of all ages. The treated sample represents too small a number to be concerned about the general equilibrium effects of the treatments. 


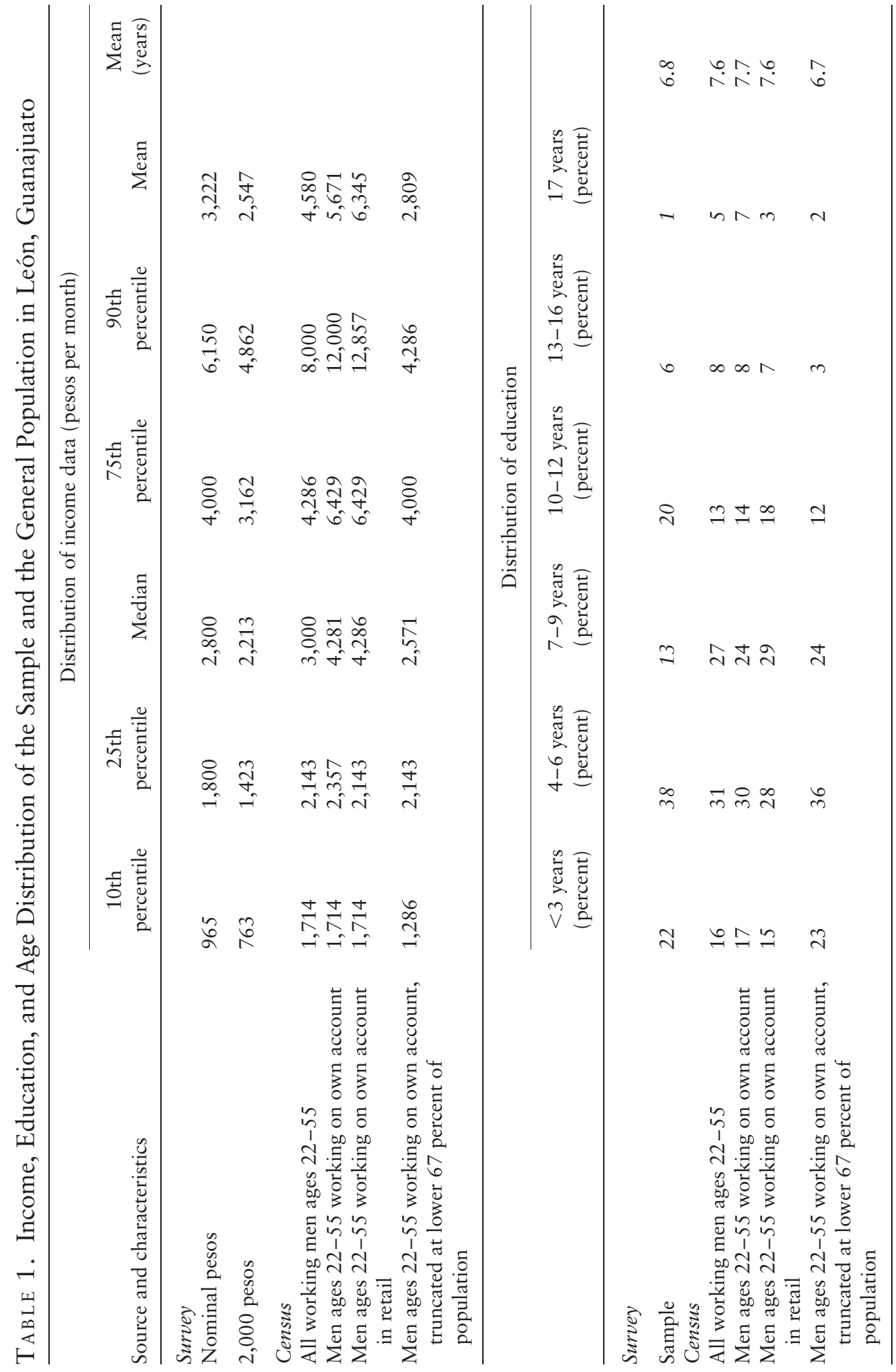




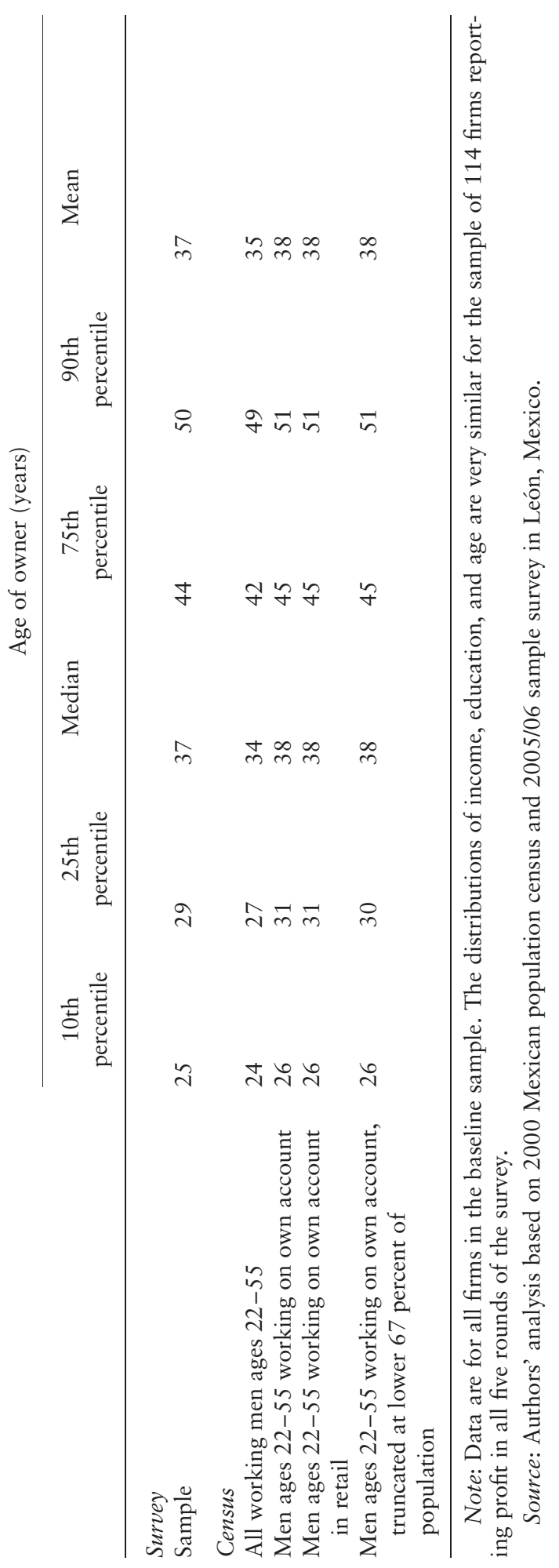


These findings are not surprising given the upper limit placed on the sample of 10,000 pesos in non-real estate capital. The upper tail of the size of enterprises is excluded from the sample. When the upper third of the income distribution is eliminated from the census sample, the distribution is quite close to that of the sample: mean income from the truncated census sample is 2,809 pesos a month (about 10 percent higher than the mean in the sample), and the difference in medians is about 16 percent. The differences are greatest in the lower tail of the distribution. ${ }^{4}$ Thus, the sample appears to represent the lower two-thirds of the income distribution of own-account workers in León.

Years of schooling of the sample also differ from those for León as a whole, with owners in the sample having less schooling (6.8 years) than those in the census $(7.7$ years). The differences are especially notable at the lowest schooling levels. In the sample, 22 percent of owners have no more than three years of schooling, and 38 percent have just four to six years. In León, among selfemployed men of same age, 17 percent have no more than three years of schooling, and 30 percent have just four to six years of schooling. Once the top third of income earners is eliminated from the census, the distribution of education matches that in the sample remarkably well: 23 percent of the selfemployed in the truncated census sample have no more than three years of schooling, and 36 percent have four to six years. The sample has a somewhat lower proportion with lower secondary schooling (13 percent compared with 24 percent in the census) and a higher proportion with upper secondary schooling (20 percent compared with 12 percent in the census).

The distribution of age is similar in the sample and the census. It is little affected by truncation of the census sample.

Overall, the data suggest that the sample accurately represents the bottom two-thirds of the sample of self-employed men in León, where own-account workers represent about 20 percent of the 22- to 55-year-old male workforce. Hence, the sample represents a sizable portion (about 14 percent) of the male labor force.

Data from the nationally representative ENAMIN can be used to determine how the capital stock of firms in our sample compares with those of other retail firms. The mean capital stock of the sample firms was 5,600 pesos at the time of the baseline survey, and the median was 5,100 pesos. The 1998 ENAMIN contains 609 own-account workers in the retail trade sector. Their enterprises have a median capital stock of 5,920 pesos and a mean capital stock of just over 18,000 pesos. Adjusting the data for inflation between 1998 and 2005, the median enterprise in the sample has a capital stock that is about 66 percent of the average own-account enterprise. As with the population

4. About one-sixth of own-account workers in the census report monthly incomes of 4,286 pesos (1,000 pesos per week). The mean income of the census sample truncated just below this level (at the 50th percentile) is 2,342 pesos; the mean of the census sample truncated just above this level is 2,797 pesos. 
census and income, truncating the ENAMIN sample at the 67 th percentile results in a distribution of enterprise capital stocks that is reasonably close to the distribution in the sample. The ENAMIN sample firms are smaller in the lower tail (700 pesos compared with 1,742 pesos, deflated to 1998 pesos, at the 25 th percentile, for example) and larger in the upper tail $(8,000$ pesos compared with 6,511 pesos, deflated to 1998 pesos, at the 75 th percentile). On average, however, enterprises in the truncated ENAMIN sample are only 12 percent larger than those in the sample.

\section{The Data}

The baseline survey was carried out in November 2005. The survey instrument was modeled after the ENAMIN survey. The first round gathered detailed information on the capital invested in the enterprise, separated by tools, machinery and equipment, vehicles, real estate and buildings, and inventories and finished and unfinished goods. It also gathered operational data on the firm (revenues, expenses, and profits) for the preceding month, as well as personal information about the owner. Each subsequent survey asked firms about the changes in capital stock (the purchase of new assets or the sale of the existing assets) and operational data for another month of the survey.

The main outcome of interest is firm profits. Profits are measured by responses to the question: "What was the total income the business earned during the month of March after paying all expenses including the wages of employees, but not including any income you paid yourself. That is, what were the profits of your business during March?" This wording is the same as in the ENAMIN survey. De Mel and others (2009) show that directly asking for profits gives a more reliable measure than taking revenue minus expenses, with the mismatch in timing between when expenses are incurred and the revenues from these expenses are realized accounting for much of the difference between the two measures. Nominal profits were then deflated into real (October 2005) profits using the consumer price index for León. ${ }^{5}$

The average enterprise has been operating for just over five years. About 20 percent of the enterprises were started within a year of the baseline survey, and almost 20 percent are at least 10 years old. Sales average 5,700 pesos a month and profits 3,486 pesos a month. The median levels of sales $(5,000$ pesos a month) and profits (3,000 pesos a month) are similar. Owners were asked about profits before accounting for any compensation for their own time, so the profit levels should be viewed as including the opportunity cost of the time spent in the enterprise by the owner. As a result, profits are never reported as being negative.

5. http://www.banxico.org.mx/polmoneinflacion/estadisticas/indicesPrecios/ indicesPreciosConsumidor.html [accessed March 17, 2008]. 


\section{The Experimental Intervention}

This section describes the experimental intervention, the staggering of treatment, attrition and noncompliance, and the volatility of monthly profit data reported by firms.

\section{The Randomized Experiment}

The randomized experiment aimed to provide exogenous shocks to the capital stock of microenterprises. This was accomplished by giving grants to a randomly selected subset of firms in the sample. Grants were used instead of loans, because the aim is to determine the marginal return to capital for the average small microenterprise, not just the microenterprise that would take up a loan with particular terms if offered such a loan. The likelihood that a microenterprise owner would take a loan would be affected by factors such as credit constraints, risk aversion, ability, beliefs about future productivity, and experiences with debt. Providing grants reveals whether greater access to capital has the potential to provide high returns to firms more generally. This can be of direct interest to governments contemplating grants for poverty alleviation, and it can show whether firms not currently borrowing have the potential to earn sufficient returns to repay loans at relatively high interest rates.

Before the first round of the survey, firms were told that the only compensation that they would receive for participating was a chance of receiving either cash or capital through prizes to be given after each survey round. ${ }^{6}$ The prize was a grant of 1,500 pesos (about \$140). After the first round of the survey, a single draw from a computerized random number generator was used to randomly assign firms to treatment and control groups. ${ }^{7}$ Among the firms assigned to treatment status, the random draw also determined the round in which they would be treated and whether they would receive their grant as cash or capital for their enterprise. The results of the initial random draw were not revealed to either the survey company or the firms in the sample. After each round, the survey company was given a list of firms to which to distribute the grants. Each firm could receive a prize at most once, although this was not made explicit to the firms.

Half of the grants were provided in cash and half as equipment or inventories. This replicates the grant process used in Sri Lanka by De Mel and

6. It does not seem plausible that forward-looking firms would have changed their behavior in expectation of compensation, as they were not told the odds of a prize and had no prior relationship with the survey firm and thus would be somewhat uncertain about whether the prizes would really be given out. In addition, the gradual roll-out of the treatment meant that untreated firms had no reason to believe the probability of treatment was so large as to make decisions based on a high likelihood of receiving treatment.

7. The sample was not stratified because all firms were owned by men in a particular age range operating in the same broad industry in the same city. Simulations on microenterprises in Bruhn and McKenzie (2008) suggest that with the sample size and the microenterprise data used here, the choice of randomization method is unlikely to matter much in terms of either balance or power. 
Table 2. Baseline Characteristics of Treatment and Control Groups

\begin{tabular}{lll}
\hline Characteristic & \multicolumn{1}{c}{$\begin{array}{c}\text { Assigned to treatment } \\
\text { group }\end{array}$} & $\begin{array}{c}\text { Assigned to control } \\
\text { group }\end{array}$ \\
\hline Age of owner (years) & 37.1 & 36.7 \\
Age of business (years) & 5.2 & 5.8 \\
Owner's education (years) & 6.6 & 6.7 \\
Mother's education (years) & 3.5 & 3.8 \\
Father's education (years) & 4.1 & 4.1 \\
Father owned a business [1 = yes] & 0.40 & 0.48 \\
Profits in Round 1 (pesos) & 3,433 & 3,312 \\
Sales in Rround 1 (pesos) & 6,063 & 6,024 \\
Non-land-owned capital in Round 1 (pesos) & 4,342 & 4,358 \\
Traveling locale [1 = yes] & 0.37 & 0.49 \\
Unregistered [1 = yes] & 0.66 & 0.65 \\
Does not keep business records [1= yes] & 0.58 & 0.55 \\
Owns house with title [1 = yes] & 0.46 & 0.48 \\
Household size (number) & 4.70 & 4.21 \\
Number of working adults in household & 1.17 & 1.30 \\
Ever had supplier credit [1 = yes] & 0.32 & 0.31 \\
Number of firms & 130 & 77 \\
\hline
\end{tabular}

Source: Authors' analysis based on the data from 2005/06 sample survey in León, Mexico.

others (2008). This mixture of grants was intended to determine whether restricted (in-kind) or unrestricted (cash) grants have different impacts. For in-kind purchases, a member of the survey team accompanied each firm to purchase whatever inputs or equipment the enterprise owner chose, under the condition that the purchase had to be for the enterprise. Cash was given without restrictions on its use. Owners were allowed to contribute funds of their own to purchase items costing more than 1,500 pesos (in practice none did). All but two firms provided with equipment grants purchased inventories or raw materials. Two purchased display cases for goods. A total of 87 firms received treatment after one of the rounds; the remaining firms did not receive any treatment. The 1,500-peso treatment represented just over a quarter of the mean or median baseline capital stock and half of median monthly profits for the enterprises. Thus, it was a substantial shock for the enterprises.

Comparison of baseline characteristics of firms assigned to treatment and control groups reveals that the randomization was successful in creating groups that were comparable in observable characteristics of owners and their firm (table 2). ${ }^{8}$ The average owner was 37 years old, and had 6.7 years of education. The majority of firms were not registered and did not keep business records. Just under half of the firms had a traveling locale, meaning that the business did not operate out of fixed premises.

8. Because assignment to groups was done randomly (meaning that by definition any such differences are due to chance), $P$-values for testing differences between the two groups are not reported. See Bruhn and McKenzie (2008) for discussion of this point. 
Table 3. Sample Size, by Survey Round

\begin{tabular}{|c|c|c|c|c|c|c|c|}
\hline \multirow[b]{2}{*}{ Round } & \multicolumn{2}{|c|}{ Ex ante design } & \multicolumn{5}{|c|}{ Actual sample ${ }^{a}$} \\
\hline & $\begin{array}{l}\text { Assigned to } \\
\text { control group }\end{array}$ & $\begin{array}{l}\text { Assigned to } \\
\text { treatment group }\end{array}$ & $\begin{array}{c}\text { Treated } \\
\text { this round }\end{array}$ & Control & Treatment & Noncompliers ${ }^{b}$ & Total \\
\hline 1 & 207 & 0 & 0 & 198 & 0 & 0 & 198 \\
\hline 2 & 194 & 13 & 9 & 155 & 8 & 3 & 166 \\
\hline 3 & 162 & 45 & 31 & 110 & 25 & 6 & 141 \\
\hline 4 & 118 & 89 & 68 & 83 & 59 & 2 & 144 \\
\hline 5 & 77 & 130 & 87 & 47 & 71 & 10 & 128 \\
\hline
\end{tabular}

${ }^{a}$ Observations in sample with nonmissing profit data.

${ }^{b}$ Firms that were assigned to receive a treatment but did not receive it. The majority of these firms did not receive a treatment because they had dropped out of the survey by the time they would have received treatment. However, some firms assigned to treatment remained in the survey but were not given the treatment because the survey firm could not locate the firm owner at the treatment should have been provided. Five of these firms were treated in a later round.

Source: Authors' analysis based on the data from 2005/06 sample survey in León, Mexico.

Table 4. Cumulative Attrition Rates, by Survey Round

\begin{tabular}{lllllll}
\hline & \multicolumn{3}{c}{ Attrition rate } & & \multicolumn{2}{c}{ With 5 percent trimming } \\
\cline { 2 - 3 } $\begin{array}{c}\text { Assigned to } \\
\text { Round }\end{array}$ & $\begin{array}{c}\text { Assigned to } \\
\text { control group }\end{array}$ & $\begin{array}{c}\text { Received } \\
\text { treatment group } \\
\text { treatment }\end{array}$ & & $\begin{array}{c}\text { Assigned to } \\
\text { Noncompliers }\end{array}$ & $\begin{array}{c}\text { Assigned to } \\
\text { control group } \\
\text { treatment group }\end{array}$ \\
\hline 2 & 0.20 & 0.15 & 0.11 & 0.25 & 0.49 & 0.46 \\
3 & 0.32 & 0.31 & 0.19 & 0.57 & 0.52 & 0.56 \\
4 & 0.30 & 0.31 & 0.13 & 0.90 & 0.49 & 0.53 \\
5 & 0.39 & 0.38 & 0.18 & 0.77 & 0.58 & 0.55 \\
\hline
\end{tabular}

Note: Attrition measured as either not in round or in round with missing profits.

Source: Authors' analysis based on data from 2005/06 sample survey in León, Mexico.

\section{Staggering of Treatment, Attrition, Noncompliance, and Noise}

The sample initially included 198 of the 207 firms reporting profits in the baseline survey (table 3 ). The number of firms dropped in each subsequent round: only 128 firms were in the survey and reported profits by the last round (table 4). The attrition rates are very similar for firms assigned to control and treatment, beginning at 15-20 percent at the start of the second round and climbing to 38-39 percent by the fifth round. Some of the attrition was reportedly caused by migration to the United States; most of it came from refusals to continue to participate and from the inability of the survey firm to relocate some firm owners in subsequent rounds. ${ }^{9}$ These rates of attrition are similar to those in the quarterly labor force panel surveys undertaken by the Mexican

9. The business locations for many firms are at most semifixed, with low costs of moving to new locations to take advantage of market opportunities in a different part of the city. 
government's statistical agency (Instituto Nacional de Estadística, Geografía, e Informática). Antman and McKenzie (2007) report an attrition rate of 35 percent over five quarters among 25- to 49-year-old household heads with wage or self-employed earnings. The fact that the attrition rates are so similar for treatment and control groups suggests that under plausible assumptions (detailed in Section III) attrition will not bias the estimates of the treatment effect. This issue is returned after the main results are presented.

Attrition is much lower among firms that actually received treatment, with only 18 percent of the treated firms dropping out by Round 5. There are several possible reasons for lower attrition among treated firms. First, in order to receive a treatment, a firm assigned to treatment had to stay in the survey and be able to be located at the time of receiving treatment. Many of the firms assigned to treatment dropped out before they were scheduled to receive treatment. Second, treatment might increase the likelihood of firm owners agreeing to continue responding to the survey, through some sense of obligation or better appreciation of the survey after receiving a prize from it. Third, treatment may prevent some firms that would have gone out of business from doing so, keeping them in the sample longer.

The selection effect can be addressed by conditioning on individuals still in the sample. The selection accounts for the majority of the difference in attrition rates between those assigned and those not assigned to treatment. A probit regression of the probability of dropping out between time $t-1$ and $t$, conditional on being in the survey at time $t-1$, gives a marginal effect of being treated of 0.08 , with a $P$-value of 0.068 . This suggests that treatment has some effect on the likelihood of a firm staying in the sample. It is not possible to determine whether firms drop out because they go out of business or because they refuse to continue to participate in the study.

In addition to attrition and noncompliance, a third factor that must be considered when estimating the effect of treatment is the high volatility of the monthly profit data reported by firms. Profits vary both across firms and for the same firm over time. In Round 1, the mean profits across firms is 3,410 pesos, with a standard deviation of 2,198 , yielding a coefficient of variation of 0.64 . The percentage change in a firm's monthly profits from one round to the next ranges from -97.6 to $+4,110$ percent. Fitting an AR(1) model with a constant to profits gives an autoregressive coefficient of only $0.31(P=0.000)$ on the quarterly lag, a surprisingly low degree of autocorrelation.

Some of this variation is undoubtedly genuine, reflecting productivity shocks, seasonality, growth, and decline. However, a substantial amount of the variation is likely to be noise. Less than 7 percent of firms use formal methods to keep business records, 34 percent use personal notes, and 58 percent keep no business accounts at all. For almost all firms, estimation of firm profits is thus based on recall and personal notes, which are likely to be subject to reporting error. Some of the estimation is therefore done by eliminating firms that have a percentage change in profits in the top or bottom tails of the 
percentage chance in profits distribution. Trimming the top and bottom 5 percent means dropping firms with a change in monthly profits, that is less than -75 percent or greater than 280 percent from one quarter to the next. ${ }^{10}$

Trimming the top and bottom 5 percent increases overall attrition to 55-58 percent by the fifth round, with only a minor difference in attrition by control and treatment groups. This trimming greatly increases the autocorrelation of profits. Estimating an $\mathrm{AR}(1)$ model with a constant for the subset of firms left after trimming the top and bottom 5 percent of percentage changes gives an autocorrelation coefficient of $0.62(P=0.000)$, exactly twice the 0.31 value in the no trimming case.

Figure 1 displays the profits data for firms that had and had not been treated at each wave, plotting real profits in each of Rounds 2 through 5 against baseline profits. The top panel shows the results with no trimming. The much larger vertical scale than horizontal scale shows that a few firms report extremely large changes in profits and makes it hard to see what is happening for the majority of the firms. Moreover, with the vertical scale going to 50,000, one cannot see the 495-peso mean difference in treated and untreated firms, so the fitted line is not shown. Trimming the top and bottom 5 percent of changes in profits removes the largest outliers, allowing the gap in fitted mean profits between treated and untreated firms to be clearly seen (bottom panel). ${ }^{11}$ This difference in mean profits between firms receiving treatment and firms not receiving treatment is a naive estimate of the treatment effect. It will be equal to the average treatment effect on the treated (ATT) only if there is no selection into treatment among firms assigned to treatment. Section III shows how to estimate the ATT even when there is selection into the treatment among those randomly assigned to receive it.

\section{Estimation of the Treatment Effect and Results}

This section begins with the estimation of the treatment effect and then presents the estimates of the intention-to-treat (ITT) effect and of the treatment effect on the treated.

\section{Estimation of the Treatment Effect}

Estimating the mean effect of being assigned to treatment on business profits requires estimating for firm $i$ in period $t$ :

$$
\operatorname{PROFITS}_{i, t}=\alpha+\beta Z_{i, t}+\sum_{s=2}^{5} \delta_{s}+\varepsilon_{i, t}
$$

10. Results are similar, but not as precise, when the top and bottom 1 percent are trimmed. Results available on request.

11. The fitted line is Real profits $(t)=a+b \times$ treated by time $t+c \times$ baseline profits $+e$, where the error term is clustered at the firm level. 
Figure 1. Real Profits in Baseline and Follow-up Rounds, before and after Trimming Large Changes in Profits
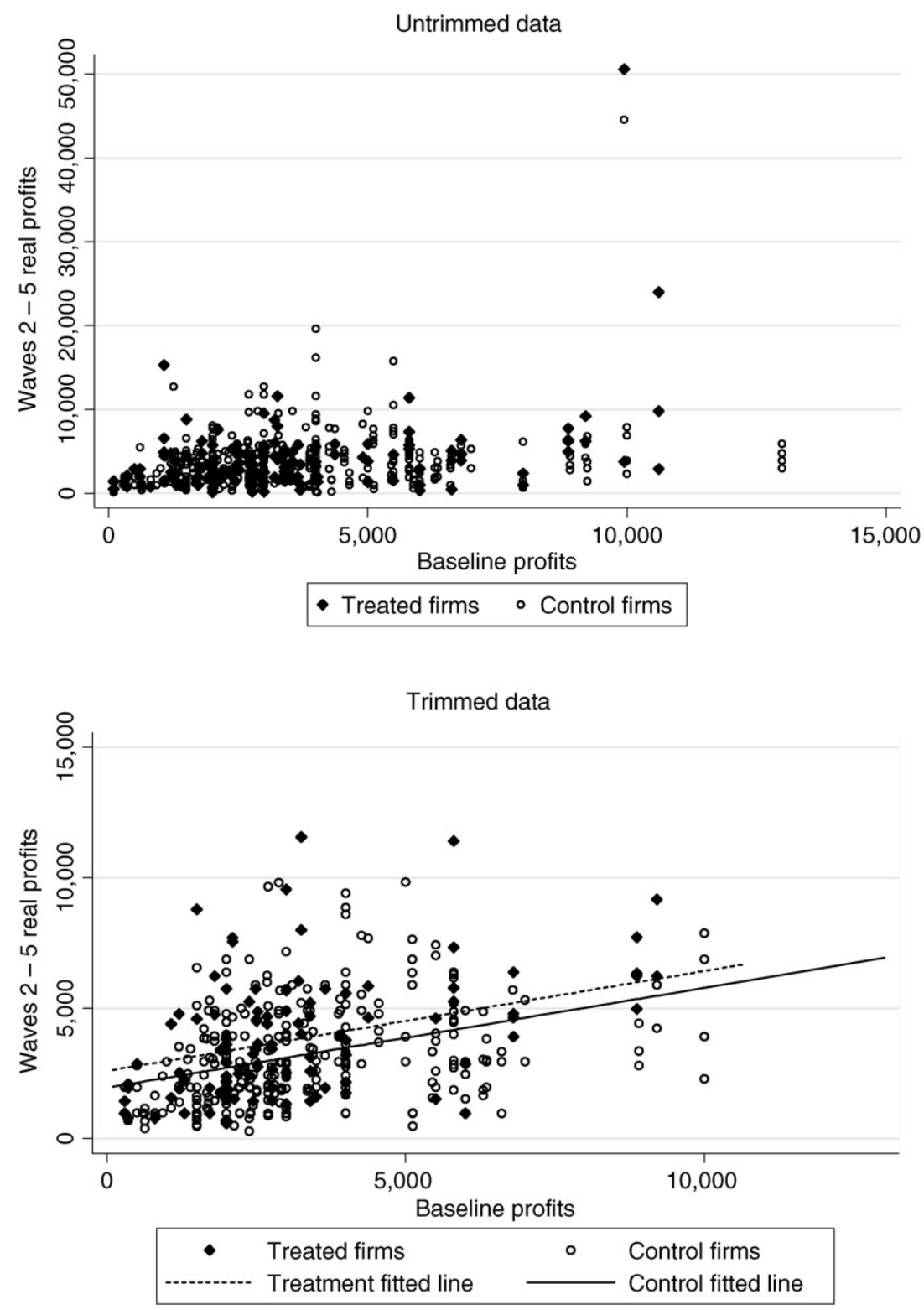

Note: Trimming removes firms with a change in profits above the 95th percentile of change in profits ( $>280$ percent) or below the 5 th percentile (less than -75 percent). The fitted line in the bottom panel is an ordinary least squares regression of real profits on a dummy variable for treatment and on baseline profits. The coefficient on treatment is 643 , with a standard error clustered at the individual level of $268(P=0.018)$.

Source: Authors' analysis based on 2005/06 sample survey in León, Mexico. 
where $Z_{i, t}$ is an indicator of whether firm $i$ has been assigned to treatment at time $t$, and $\delta_{s}$ are period effects. The cash and equipment treatments are pooled into a single treatment for greater power (the two groups are separated later). The coefficient $\beta$ gives the average effect of being assigned to treatment, also known as the ITT effect. Randomization means that the expected correlation between the error term $\varepsilon_{i, t}$, and $Z_{i, t}$ is zero, implying that ordinary least squares can be used to estimate equation (1), clustering the error term at the firm level. However, because there are multiple observations for the same firms, the error term $\varepsilon_{i, t}$ is likely to have a firmspecific component that can be controlled for through random-effects estimation. As a further check, fixed-effects estimation is also carried out. The advantage of fixed effects is that they will capture any time-invariant firm characteristics that affect profits. As shown in table 2, randomization appears to have provided comparable assignment to control and treatment, making this less necessary. A second possible use of fixed effects is to potentially increase the precision of the results, by lowering the residual variance. Because profit data are believed to be subject to measurement error, however, using fixed effects may decrease the signal-to-noise ratio, thereby reducing precision.

The ITT effect shows the overall impact of the experiment. Interest in this parameter by policy makers may be limited, because the experiment does not examine the implementation of an actual program. Given the success of the Progresa/Oportunidades program in using conditional cash transfers to reduce poverty, however, it is conceivable that governments may consider conditional cash transfers to low-income firm owners as another form of poverty alleviation.

For most policy purposes, policy makers would like to know the impact of actually receiving the treatment, $\lambda$, in the following equation:

$$
\operatorname{PROFITS}_{i, t}=\theta+\lambda \operatorname{TREAT}_{i, t}+\sum_{s=2}^{5} \pi_{s}+v_{i, t}
$$

where TREAT $_{i, t}$ is an indicator of whether firm $i$ actually received treatment by time $t$. The coefficient $\lambda$ can be estimated using $Z_{i, t}$ (whether or not a firm was assigned to treatment) as an instrument for receiving treatment. This estimate, known as the local average treatment effect (LATE), can be interpreted as the effect of the treatment on individuals who receive treatment after being assigned to treatment. Angrist (2004) demonstrates that in situations in which no individuals who are assigned to the control group receive the treatment, as is the case here, the LATE is the same as the ATT. As with estimation of equation (1), estimation of equation (2) allows the error term to be clustered at the firm level, has a random effect, or has a fixed-effects component. 


\section{Results}

Consider first the ordinary and two-stage least squares results (table 5). The ITT estimates range from 543 to 603 pesos; the treatment effect on the treated (TOT) estimates range from 608 to 685 pesos. Comparing these results with the treatment given to firms of 1,500 pesos (about $\$ 140$ ) reveals a very large treatment effect. With 5 percent trimming, the TOT effect is equivalent to a 46 percent return on the treatment, significant at the 10 percent level. The random-effects estimates show slightly smaller treatment effects, with the TOT ranging from 264 to 527 pesos. After 5 percent trimming, the TOT is equivalent to a 35 percent return on the treatment, significant at the 5 percent level.

The raw results from fixed-effects estimation are the only exception to the pattern of large treatment effects. The TOT effect is -19.4 pesos, with a standard error of 449. This appears to be a result of the noise in the data swamping any signal once the fixed effects are taken out. Indeed, as the data are trimmed and the amount of noise reduced, the fixed-effects estimates also show positive treatment effects. The TOT effect with 5 percent trimming is 432 pesos, corresponding to a 28.8 percent return. The $P$-value is 0.141 , close to a standard significance level even after having removed a large amount of the signal from the data.

The results from table 5 show the treatment effects that are significant for two-stage least squares and instrumental variables random-effects estimation and marginally significant for instrumental variables fixed-effects estimation after 5 percent trimming. The estimated treatment effect ranges from 28.8 to 45.6 percent. It is well identified only for the subset of firms without very noisy profit data that take up the treatment when assigned.

Interpreting the TOT as a return to capital requires assuming that the treatment affects profits only through changes in the capital stock. The firms in the survey had no paid employees, and over the short time it seems unlikely that the treatment affected management ability or total factor productivity. Thus, the only other channel through which the treatment may have affected profits is adjustments in the labor supply of the owner. Estimating equation (1) with own hours as the dependent variable gives an ITT effect of -3.7 , with a $P$-value of 0.09 . This falls to an effect of -2.1 and a $P$-value of 0.27 when hours are restricted to be above zero and below 100 a week. Ignoring the changes in own hours is justified by the lack of significance after removing outliers; it leads the estimates to be a lower bound on returns to capital. Alternatively, an ordinary least squares regression on the baseline data suggests that the marginal value of one additional hour of own labor is 15 pesos. Valuing the fall in labor at this rate would raise the random-effects treatment effect in column 4 of table 5 from 527 to 724 pesos, increasing the return to capital to 48 percent.

Pooling Cash and Equipment Treatments. The analysis so far has pooled the cash and equipment treatments. The first two columns of table 6 report the results of allowing the effect of the treatment to vary according to the form it 


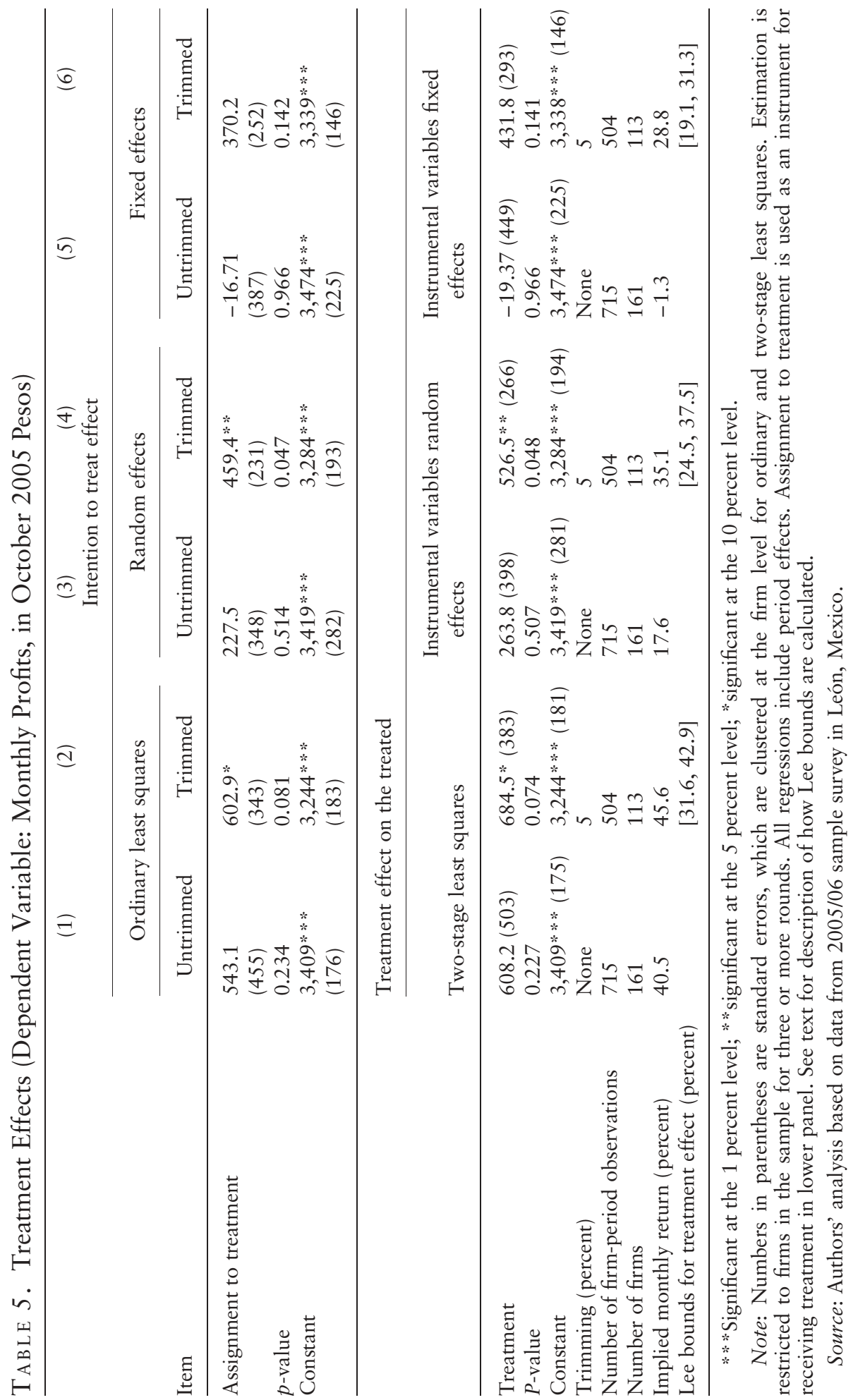




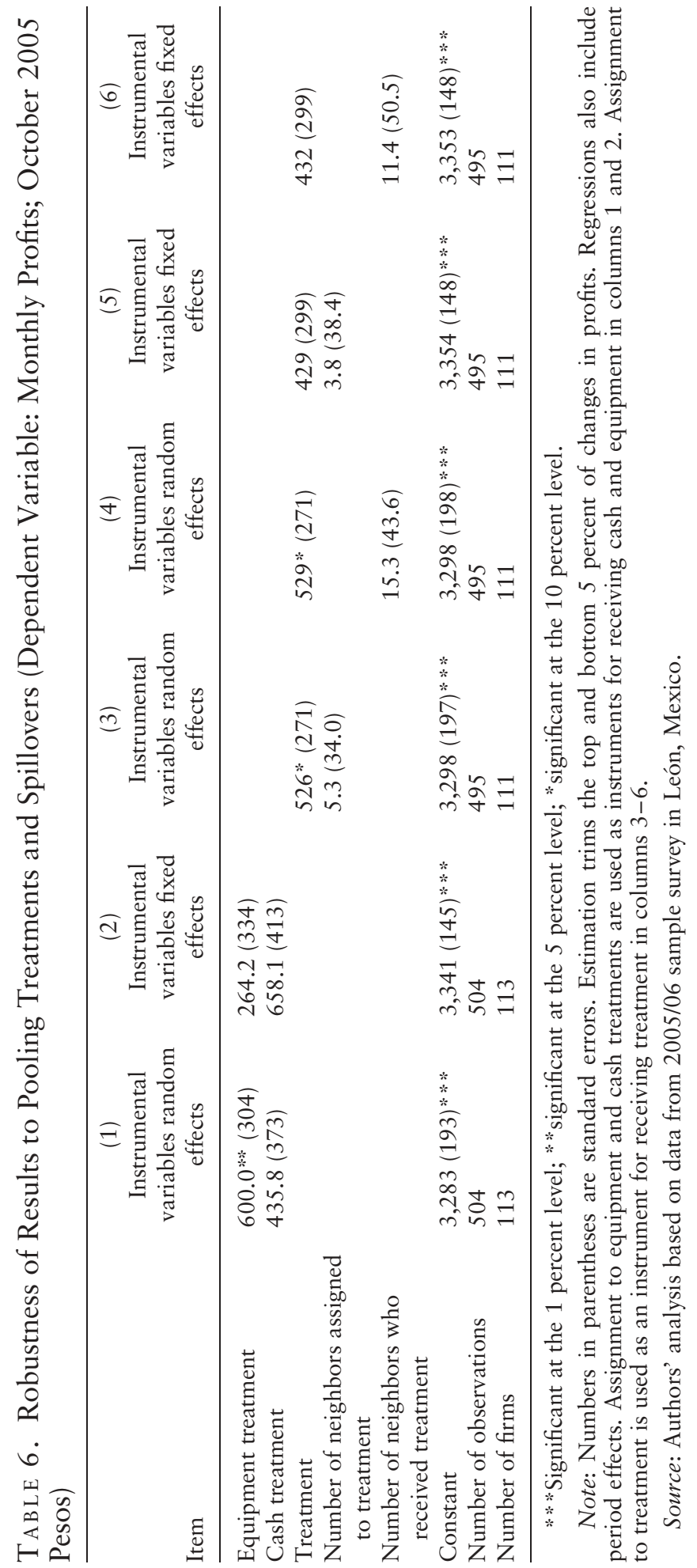


is given in. Under random effects, the TOT is 600 pesos for the equipment treatment and 436 pesos for the cash treatment. The null hypothesis that the two effects are equal in size, justifying pooling the treatments, cannot be rejected. Using fixed effects generates a larger point estimate for the cash treatment than the equipment treatment, but the hypothesis that the two treatments have the same effect cannot be rejected. There is thus not sufficient power to rule out the null hypothesis of no difference in effects between conditional and unconditional grants to microenterprise owners.

SPILLOVERS. The treatment effect is estimated by comparing firms randomly assigned to treatment group with firms randomly assigned to the control group. This yields a valid estimate of the treatment effect, provided that there are no spillover effects from the treatment to the control sample. The validity of this assumption is investigated by adding the number of other firms within the same census sampling cluster (UPM) as a firm that has either been assigned to treatment or actually received treatment. Over Rounds 2 through 5, the median firm had 1, the mean had 2.1, and the 90th percentile had 7 firms receiving treatment in the same UPM. The spillover effect is estimated to be small, positive, and not statistically significant; the coefficients on the treatment effects are very similar to those shown in table 5. Thus, there does not seem to be any evidence of spillover effects. The treatment effects can thus be interpreted as pure treatment effects.

ATtRITION. One potential concern is whether the process of trimming combined with attrition could be biasing the results. Attrition rates are similar for firms assigned to the control and treatment groups. However, after 5 percent trimming, attrition after five rounds is 58 percent for the control group and 55 percent for the group assigned to treatment. The bounding approach of Lee (2005) is used to construct upper and lower bounds for the treatment effect in order to examine the robustness of the results to this differential attrition. ${ }^{12}$

The key identifying assumption required for implementing the Lee bounds is a monotonicity assumption that posits that treatment assignment affects sample selection in only one direction. In the present context, it requires assuming that some firms would have dropped out if they had not been assigned to treatment but that firms do not drop out because they are assigned to treatment. This seems plausible, as firms receiving treatment may be less likely to

12. An alternative approach is to model attrition parametrically and use the predicted model to reweight the data. However, attrition is not related to the age of the firm, education of the owner, whether or not the firm is registered, baseline profits, the type of location of firm, or household size. A parametric correction for attrition by using weighted least squares to account for differences in the probability of staying in the sample of different firms increases the two-stage least squares estimate from 685 to 806 . With a standard error of 425 , the hypothesis that there is no change in the coefficient from attrition cannot be rejected, but if anything this parametric correction for attrition increases the estimated return to capital. 
fail and more likely to be willing to answer the survey question. It does not appear likely that receiving treatment would have caused some firms to drop out of the survey that would not have dropped out if they had remained in the control group.

To construct the Lee bounds, one trims the distribution of profits for the group assigned to treatment by the difference in attrition rates between the two groups as a proportion of the retention rate of the group assigned to treatment. A lower (upper) bound on the treatment effect is constructed by trimming the upper (lower) tail of the distribution. This requires trimming the upper or lower 6.7 percent of the profits distribution for the group assigned to treatment.

The last row of table 5 provides the upper and lower Lee bounds for the TOT effect after 5 percent trimming, adjusting for differential attrition between the groups assigned to control and treatment. As a result of the skewed distribution of profits, the point estimates in table 5 are much closer to the upper bounds than to the lower bounds. The lower bound for the treatment effect is 19.1 percent for the instrumental variables fixed-effects estimate, 24.5 percent for the instrumental variables random-effects estimate, and 31.6 percent for the two-stage least squares estimate. Thus, in all cases, even the lower bound shows a large effect of the treatment.

\section{Returns and Access to Finance}

In Mexico, returns are much higher than interest rates offered by banks and microfinance firms. The leading explanation for such high returns is that many of the firms are credit constrained, causing them to operate below their efficient size. If this is the case, one should expect firms that are more credit constrained to have higher returns from the treatment. This possibility is explored by interacting the treatment effect with different measures of whether or not a firm is credit constrained, using the following estimation equation:

$$
\begin{aligned}
\text { PROFITS }_{i, t}= & \theta+\lambda \operatorname{TREAT}_{i, t}+\varphi \mathrm{TREAT}_{i, t} * \mathrm{UNCONSTRAINED}_{i} \\
& +\sum_{s=2}^{5} \pi_{s}+\sum_{s=2}^{5} \delta_{s} * \mathrm{UNCONSTRAINED}_{i}+v_{i, t}
\end{aligned}
$$

where the period effects are allowed to vary with the measure of whether or not firm $i$ is financially constrained. The level effect for being unconstrained is also included in this regression when random effects are used, but it drops out when fixed effects are used. Assignment to treatment and the interaction of assignment to treatment with being unconstrained are used as instruments for receiving treatment and its interaction with being unconstrained.

The data provide several possible measures of access to finance and financial constraints from the baseline survey (table 7). The first is a question that asks 


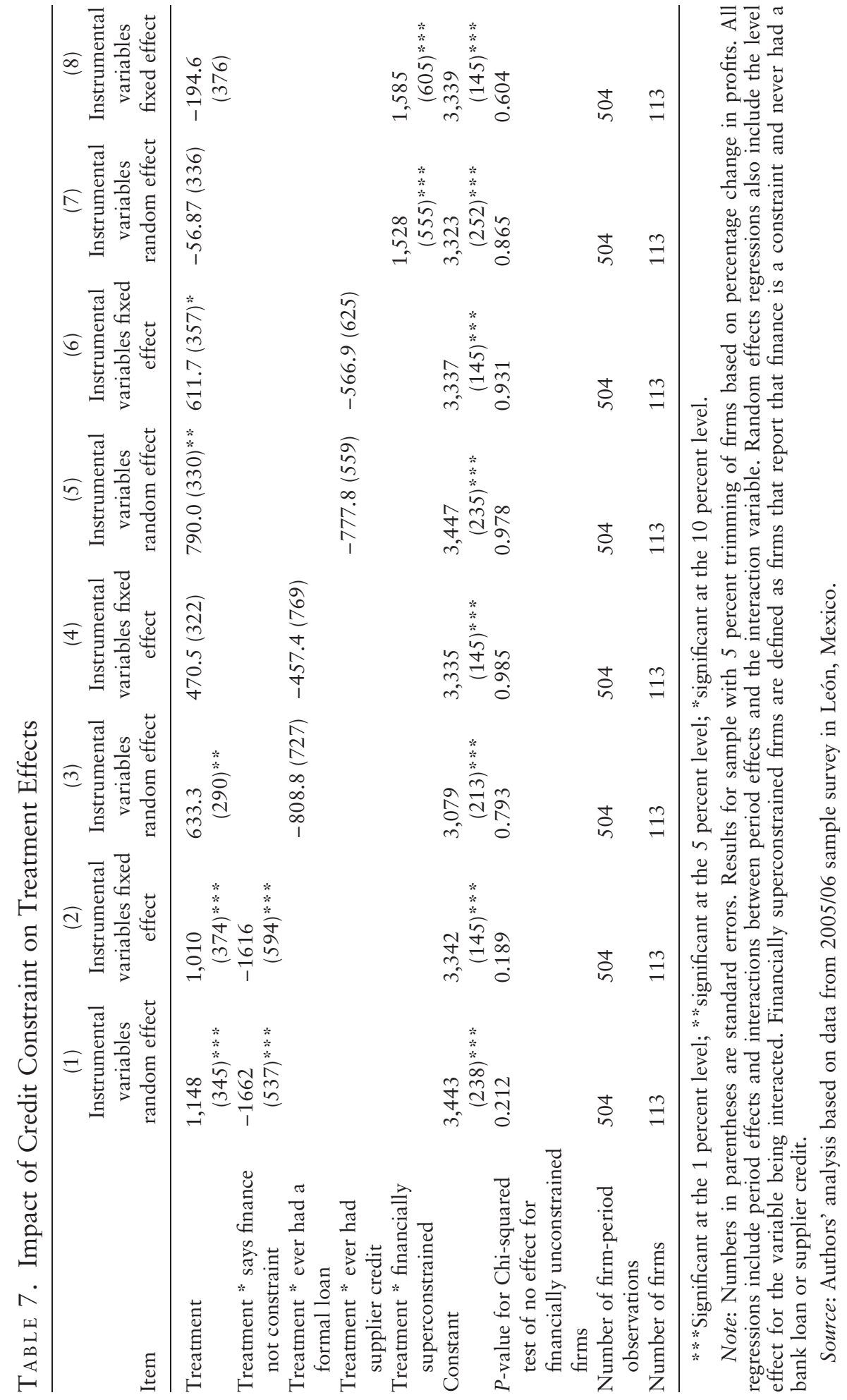


firm owners whether lack of finance is an obstacle to the growth of their business. Sixty-four percent of firm owners report that it is a constraint. Owners with more education and whose father owned a business are less likely to report that finance is a constraint. The other measures are objective measures of the use of finance: whether or not firms had ever used formal finance or supplier credit at the time of the baseline survey. Firm owners with previous use of formal loans or supplier credit may be less financially constrained than other owners. Just 15.6 percent of firms had ever had a formal loan, and 31.7 percent had ever had supplier credit. Formally registered firms are more likely to have had a formal loan or supplier credit. However, the measures of use of finance are only very weakly positively correlated with selfreporting that finance is not a constraint, with a correlation between reporting that finance is not a constraint and having previously had a formal loan of just 0.036 .

Estimates of the treatment effects allowing for interactions between treatment and different measures of lack of financial constraints are reported after again eliminating firms with percentage changes in profits below the 5 th percentile or above the 95th percentile. Columns 1 and 2 of table 7 show a large and strongly significant interaction effect between treatment and whether a firm owner reports that finance is not a constraint to business growth. One cannot reject the possibility that firms that report that finance is not a constraint have no increase in profits from the treatment (the point estimate actually shows a decrease in profits). The treatment effect is much stronger for the 64 percent of firms that report that finance is a constraint: monthly profits increase 1,051-1,192 pesos for these firms, a 70-79 percent return. Similar but less significant interaction effects are found for the measures of previous use of credit. One cannot reject the possibility that there is no treatment effect for firms that previously had formal loans or supplier credit; the treatment effect for financially constrained firms is always positive, and it is significant in all but one case (firms that have not had a formal loan).

The different measures are combined to create a set of firms that report that finance is a constraint to business growth and that have never had a formal loan or supplier credit. The 38 percent of firms that fall into this category are referred to as "financially superconstrained." Interacting this variable with the treatment increases the profits among these firms by $1,430-1,515$ pesos-an incredible 100 percent return.

\section{Discussion and Conclusion}

Returns to capital are difficult to measure because of numerous problems. Among the smallest firms, managed by their owners, both the firm's profits and the level of capital stock may be correlated with the unmeasured ability of the owner, with unmeasured factors affecting demand for the firm's products, or 
with both. These issues are overcome in a sample of small retail enterprises in Mexico by generating random shocks to capital stock in a field experiment.

The data imply that profits increase by 300 to 1,500 pesos (for superconstrained firms), a 20-100 percent monthly return on the 1,500 pesos given to treated firms. Such large estimates are plausible for several reasons. First, the analysis is limited to firms in the retail sector with replacement costs of capital less than $\$ 900$ whose owners work full time in the enterprise. Using a broader sample of Mexican enterprises, McKenzie and Woodruff (2006) find average monthly returns on capital of 10-20 percent for firms with capital stock below $\$ 200$. For firms with capital stock of $\$ 500-\$ 1,000$, they find returns on capital in the 5 percent range.

Second, the treatment effect is negligible for firms that report no financial constraints (see table 7). The results, therefore, reflect the experience of a relatively select group: firms with capital stock near \$200 that report being financially constrained.

Borrowers from microfinance institutions may match these characteristics reasonably well. Being a client of such an institution is evidence that an individual feels financially constrained; many clients are likely to operate microenterprises in sectors that require only a small amount of capital. Compartamos, the largest pure microlender in Mexico, charges an average annual interest rate of 105 percent on loans made primarily to solidarity groups composed of three to eight women. ${ }^{13}$ Such groups are liable for any default; members thus have a strong incentive to monitor and assist one another to ensure repayment. Without group liability, one would expect lending rates to be higher. ${ }^{14}$ Using the lower bound for the treatment effect (roughly 25 percent), a treated firm could repay a 1,500 peso loan in four to five months. Thus, the interest rates charged by Mexican microlenders, though high by the standards of microlenders in other countries, are affordable to the segment of the population represented by the sample firms. If the annual rate on an individual loan were twice that of a loan to a solidarity group, sample firms would still, on average, be able to repay the loan from profits earned. That the rates charged by the largest microlender are roughly similar to the estimates provides support for the plausibility of the regressions.

Additional support for the notion that returns are especially high for the type of firms in the sample comes from comparisons with microlenders that focus on larger firms. The MIX Market, a Web-based platform for the global exchange of information in the microfinance industry, provides data on four leading Mexican microlenders. These data suggest that return on

13. The interest rate figure comes from Carlos Labarthe, the co-CEO of Compartamos, as reported in Bruck (2006). When all costs are considered, the actual interest rate on some Compartamos loans is near 120 percent.

14. The exact role of group compared with individual liability is still being debated. Giné and Karlan (2006) suggest that switching from group to individual liability does not affect repayment rates. 
equity and average loan size are negatively correlated. Caja Popular Mexicana had an average loan size of $\$ 1,429$ and a return on equity of 10.5 percent in 2005. Compartamos and Finca México, which focus on small borrowers (with average loan sizes of $\$ 399$ and \$242), had much higher returns on equity (55.2 and 34.2 percent). ${ }^{15}$ FinComun falls between the two group for both measures, with loans averaging $\$ 635$ and a return on equity of 25.2 percent. The data thus suggest that returns are highest for microfinance institutions that make small loans. Those institutions have loan sizes substantially larger than the $\$ 140$ received by treated firms in the experiment. Given the peculiarities of the Mexican context, the returns estimated here are thus not implausible.

The high returns to capital at these very low levels of capital stock have several important implications. First, they suggest that there is no minimum investment threshold below which returns to capital are so low that entry into self-employment is discouraged. This suggests that capital constraints operating through occupational choice is not a cause of permanent poverty traps. Capital constraints are still plausibly a source of some inefficiency. The finding that returns are highest among the most constrained enterprises supports this notion. Capital may not flow to these firms despite high returns for a number of reasons, including the cost of servicing small loans, lack of collateral, a weak contracting environment, and large information asymmetries (Morduch 1999).

Second, the existence of high returns contributes to the debate on how best to increase the access to financial services among the poor (Morduch 1999; Armendáriz and Morduch 2007). One view is that it can be profitable to do so only with highly subsidized interest rates (provided through subsidized microfinance institution or government banks). A contrasting view is that at least some of the poor have the capacity to repay loans at much higher rates, enabling microfinance institutions to be self-sustaining. The results presented here show that the average financially constrained microenterprise in the retail trade sector has very high returns, at a level sufficient for it to be able to repay high interest rates. ${ }^{16}$ But these high returns also present a puzzle. On average, the enterprises in the sample are five years old. Given the high returns to capital in the enterprises and the lack of any investment threshold, one might wonder why the owners have not grown on their own accord by reinvesting profits from the enterprise. This is a topic for future research.

15. Finca México is a so-called village lender, a group lending technology in which each branch forms a single, large group and is given a degree of self-governance. This could explain why its return on equity is lower than that of Compartamos despite having a smaller average loan size.

16. Of course, one reason why the returns are so high is that these firms are financially constrained. Given rapid expansion in access to credit, one would expect these returns to fall. Currently, returns are high enough for interest rates not to be the main constraint to access to financial services. 


\section{REFERENCES}

Angrist, Joshua. 2004. "Treatment Effect Heterogeneity in Theory and Practice." Economic Journal 114(494):C52-C83.

Antman, Francisca, and David McKenzie. 2007. "Earnings Mobility and Measurement Error: A Pseudo-Panel Approach.” Economic Development and Cultural Change 56(1):125-62.

Armendáriz, Beatriz, and Jonathan Morduch. 2007. The Economics of Microfinance. Cambridge, MA: MIT Press.

Banerjee, Abhijit, and Esther Duflo. 2004. Do Firms Want to Borrow More? Testing Credit Constraints Using a Directed Lending Program. BREAD Working Paper 005, Bureau of Research and Economic Analysis of Development, Duke University, Durham, NC, USA.

Bruck, Connie. 2006. "Millions for Millions.” The New Yorker, October 30.

Bruhn, Miriam, and David McKenzie. 2008. In Pursuit of Balance: Randomization in Practice in Development Field Experiments. World Bank, Development Research Group, Washington, D.C.

De Mel, Suresh, David McKenzie, and Christopher Woodruff. 2008. "Returns to Capital in Microenterprises: Evidence from a Field Experiment." Quarterly Journal of Economics 123(4):1329-72.

- 2009. "Measuring Microenterprise Profits: Must We Ask How the Sausage Is Made?” Journal of Development Economics 88(1):19-31.

Giné, Xavier, and Dean Karlan. 2006. Group versus Individual Liability: A Field Experiment in the Philippines. Policy Research Working Paper 4008. World Bank, Washington, D.C.

Karlan, Dean, and Jonathan Zinman. 2008a. "Credit Elasticities in Less-developed Economies: Implications for Microfinance.” American Economic Review 98(3):1040-68.

.2008b. Expanding Credit Access: Using Randomized Supply Decisions to Estimate the Impacts. New Haven, CT: Department of Economics, Yale University.

Kremer, Michael. 2003. "Randomized Evaluations of Educational Programs in Developing Countries: Some Lessons." American Economic Review Papers and Proceedings 93(2):102-06.

Kremer, Michael, Jean Lee, and Jonathan Robinson. 2007. "The Return to Capital for Small Retailers in Kenya: Evidence from Inventories." Paper presented at the Northeast Universities Development Consortium conference, October 26-27, Harvard University, Cambridge, MA, USA.

Lee, David. 2005. Training, Wages, and Sample Selection: Estimating Sharp Bounds on Treatment Effects. NBER Working Paper 11721. Cambridge, MA: National Bureau of Economic Research.

McKenzie, David J., and Christopher Woodruff. 2006. "Do Entry Costs Provide an Empirical Basis for Poverty Traps?” Economic Development and Cultural Change 55(1):3-42.

Morduch, Jonathan. 1999. "The Microfinance Promise." Journal of Economic Literature 37(4): 1569-614.

- 2000. "The Microfinance Schism.” World Development 28(4):617-29.

Udry, Christopher, and Santosh Anagol. 2006. "The Return to Capital in Ghana.” American Economic Review 96(2):388-93. 